\title{
The effects of different irrigation solutions on the bond strength of cemented fiber posts
}

This article was published in the following Dove Press journal:

Clinical, Cosmetic and Investigational Dentistry

\author{
Fahad I Alkhudhairy' \\ Peter Yaman ${ }^{2}$ \\ Joseph Dennison ${ }^{2}$ \\ Neville McDonald ${ }^{2}$ \\ Alberto Herrero ${ }^{3}$ \\ Mohammed S Bin-Shuwaish' \\ 'Department of Restorative Dental \\ Sciences, College of Dentistry, King \\ Saud University, Riyadh, Kingdom \\ of Saudi Arabia; ${ }^{2}$ Department of \\ Cariology, Restorative Sciences \\ and Endodontics, School of \\ Dentistry, University of Michigan, \\ Ann Arbor, Michigan, USA; ${ }^{3}$ Biologic \\ and Materials Sciences, School of \\ Dentistry, University of Michigan, Ann \\ Arbor, Michigan, USA
}

Correspondence: Fahad I Alkhudhairy Department of Restorative Dental Sciences, College of Dentistry, King Saud University, P.O. Box 60169, Riyadh I I545, Kingdom of Saudi Arabia Email falkhudhairy@ksu.edu.sa
Objective: To study effect of root canal irrigant solutions on the bond strength of cemented fiber posts, and resin cement-tags in root canal dentin.

Materials and methods: Fifty-two human single-rooted anterior teeth were selected and stored in $1 \%$ sodium azide. Crowns were sectioned $2 \mathrm{~mm}$ incisal to the cemento enamel junction with diamond bur at high speed under water-cooling. After standard root canal treatment to tested teeth, they were randomly assigned into four groups $(n=13)$ corresponding to the endodontic irrigant solution that was used during post space preparation. The treatment groups were: Group 1: $6.15 \%$ sodium hypochlorite; Group 2: 17\% EDTA; Group 3: 6.15\% NaOCl +17\% EDTA; Group 4: $6.15 \% \mathrm{NaOCl}+0.12 \%$ chlorhexidine solution. Parallel-sided fiber posts were used for all specimens. Samples were embedded in a cylindrical PVC mounting jig to facilitate perpendicular sectioning. With low speed diamond saw, cervical and apical specimens from each tooth were obtained and subjected to push-out test using universal testing machine. SEM was used to examine the root-canal dentin surface.

Results: Statistical analysis revealed significant difference among the groups at $P<0.05$. Group 2 treated with EDTA, had the highest bond strength; 18.63 $2.85 \mathrm{MPa}$ in cervical specimens and 13.49 $\pm 3.67 \mathrm{MPa}$ in apical specimens. The cervical specimens of Groups 2 and 3 were significantly different than the apical specimens in the same group. Adhesive failure between cement and dentin was the main failure mode observed in all groups. Groups irrigated with EDTA showed cleaner dentin surface and better resin tag formation, while groups treated with $\mathrm{NaOCl}$ showed less resin tag formation and insufficient smear layer removal.

Conclusion: $\mathrm{NaOCl}$ had adverse effect on bond strength of self-adhesive resin cement to radicular dentin. EDTA irrigant solution produced higher bond strength and was more effective in removing smear layer than $\mathrm{NaOCl}$.

Keywords: bond strength, fiber posts, irrigation solution, resin cement

\section{Introduction}

Restoring endodontically treated teeth by composite resin build up using fiber post with adhesive resin cement had been widely accepted and gained more recognition. ${ }^{1}$ Cementing the post to the root canal dentin is a difficult procedure due to several factors like access to the root canal is limited, absence of direct vision and moisture control. Self-adhesive cements have various application techniques and chemical compositions that influence the performance of bonding. Self-adhesive resin cement was fabricated to make the cementation procedures simple and reduce the sensitivity technique associated with multiple-step adhesive systems. ${ }^{2-5}$ However, the bonding mechanism of self-adhesive resin cement can still be completely misunderstood. These 
resin cements have a low demineralization effect; therefore, microleakage between cement and dentin was more evident than with the other adhesive systems. ${ }^{6,7}$ The bond strength between the cement and dentin is affected by many factors such as moisture contamination, root canal dentin hydration, unfavorable root canal configuration, the smear layer, cementation approach, and endodontic irrigant solutions. ${ }^{8,9}$

The endodontic irrigant solution primarily used is sodium hypochlorite $(\mathrm{NaOCl})$ that has the capability to dissolve organic tissues and eliminate or reduce microorganism in a root canal. ${ }^{10,11}$ After irrigating the root canal with any endodontic irrigant solution, chemical residues will diffuse along the dentinal tubules then affect the penetration of resin or inhibit the polymerization process of resin cement. ${ }^{12,13}$ Furthermore, EDTA is another important irrigant solution that can be used to remove non-organic content, especially the smear layer during root canal therapy or post space preparation. ${ }^{10,11}$ Recently, chlorhexidine has been used in the endodontic therapy to disinfect the root canal. Chlorhexidine is a broad spectrum antiseptic solution; however chlorhexidine creates a precipitate when reacted with $\mathrm{NaOCl}{ }^{14}$ In different studies, $\mathrm{NaOCl}$ and hydrogen peroxide $\left(\mathrm{H}_{2} \mathrm{O}_{2}\right)$ irrigant solutions were found to reduce the bond strength between dentin and luting resin cement and increase the microleakage. ${ }^{15}$ The increase in the $\mathrm{NaOCl}$ application time resulted in a progressive decrease in the bond strength (38\%). ${ }^{16}$ Perhaps this action is due to an oxygen rich layer forming along the dentin surface after the irrigants. This phenomenon occurs because $\mathrm{NaOCl}$ breaks down into chlorine and oxygen. Several reports have shown that anti-oxidant agents can eliminate the oxygen rich layer, and consequently improve the interaction between dentin and resin cement. ${ }^{17,18}$ Therefore, attention has been given to the effect of different endodontic irrigant solutions on the interaction of different adhesive systems and radicular dentin. ${ }^{19-21}$

The null hypothesis are as follows: H0: There is no statistically significant difference among different irrigant solutions on the bond strength of fiber posts cemented with resin cement. H1: There is a statistically significant difference among different irrigant solutions on the bond strength of fiber posts cemented with resin cement.

The aim of this in vitro study was to evaluate the effect of different endodontic irrigant solutions on bond strength of fiber posts cemented with resin cement, and to evaluate the effect of the irrigant solutions on resin tag formation in root canal dentin.

\section{Materials and methods}

This research study was reviewed and approved by the College of Dentistry Research Center (CDRC) of King Saud University, Riyadh, Saudi Arabia under CDRC Research Project no. FR 0227. A written informed consent was obtained from all the participants who agreed to include their extracted teeth in the study after explaining the objectives of the study.

Fifty-two sound human single-rooted anterior teeth were selected and stored in $1 \%$ sodium azide. Teeth with craze lines, erosion, caries, or endodontically treated were excluded.

The crowns were sectioned $2 \mathrm{~mm}$ incisal to the cemento enamel junction (CEJ) with a diamond bur at high speed under water-cooling. The working length was determined by using a size $10 \mathrm{~K}$ hand file (Dentsply; Maillefer Instruments, Ballaigues, Switzerland) then subtracting $1 \mathrm{~mm}$ from the total length to preserve the apical foramen. Sequential hand filing up to size 25 was used to enlarge the canal space in conjunction with $2 \mathrm{~mL}$ of $6.15 \% \mathrm{NaOCl}$ irrigant solution between each file size. ProFile series 29 system (Dentsply Tulsa Dental, Chattanooga, TN, USA) was used in a crown down sequence $(0.46,0.36$, and 0.27 ) repeatedly until achieving a master apical file (MAF) of 0.46 . Once the MAF was achieved, a final flush with $2 \mathrm{~mL}$ of $17 \%$ EDTA for 20 seconds was then used to irrigate the root canal. The canals were dried with paper points, and coated with AH-26 sealer (Dentsply DeTrey, Konstanz, Germany) by using a $20 \mathrm{~K}$ file rotated counter-clockwise. A gutta-percha master cone coated with AH-26 sealer was condensed into the canal using an endodontic condenser and plugger.

After the root canal treatment was completed, the teeth were randomly assigned to four groups $(n=13)$ corresponding to the endodontic irrigant solution that was used during post space preparation. The treatment groups were as follows:

- Group 1: 6.15\% NaOCl (Clorox Co., Oakland, CA, USA)

- Group 2: 17\% EDTA (Roydent Dental Products, Johnson City, TN, USA)

- Group 3: Combination of 6.15\% NaOCl and 17\% EDTA

- Group 4: 0.12\% Chlorhexidine solution (Midway Dental Co., Lakeville, IN, USA)+6.15\% NaOCl

A size \#6, parallel-sided, fiber post of $15 \mathrm{~mm}$ in length $\times 1.5$ $\mathrm{mm}$ in diameter (ParaPost ${ }^{\circledR}$ Fiber Lux, Coltène Whaledent Group, Cuyahoga Falls, OH, USA) was used for all specimens. To create an $11 \mathrm{~mm}$ post space, condensed gutta-percha was removed by using a hot plugger. For each group, the post space on the treated tooth was irrigated with $2 \mathrm{~mL}$ of the tested irrigant solution. With a low speed hand piece, sequential reamers (ParaPost Fiber Lux, Coltène Whaledent 
Group), with rubber stoppers, were inserted $11 \mathrm{~mm}$ inside the canal and shaped using an in-out motion until reaching the appropriate dimensions. In between the use of each drill, the post space was irrigated with the assigned solution. To ensure an accurate $11 \mathrm{~mm}$ insertion depth, a rubber stopper was attached to each drill. After the post space was completed, a final flush with the same solution was applied for 20 seconds. The post space was then dried using paper points.

A fiber post was passively seated inside the canal. To ensure the post reached proper depth, a rubber stopper at $11 \mathrm{~mm}$ was used with the fiber post during try in. Self-adhesive resin cement (Clearfil SA cement, Kuraray America, Inc., New York, NY, USA) was used to cement the fiber post in the treated teeth according to the manufacturer's guidelines as follows:

1. To mimic a tooth in the alveolar socket, root surfaces were wrapped with black electrical tape to convey light cure inside the root.

2. After drying the canal, the cement paste was mixed and applied into the canal using an intra-oral mixing tip.

3. The fiber post was inserted to full depth of the canal using slight vibration and firm finger pressure.

4. Excess cement was removed before light curing

5. Light cure was applied at the top of the post for 40 seconds.

Samples were stored in $100 \%$ humidity for seven days until the testing procedures were performed.

For testing purposes, each group was subdivided into two groups. The first subgroup $(n=3)$ was analyzed with SEM to evaluate bonding quality, including length, width, and lateral branches of resin tags in all specimens. The second subgroup $(n=10)$ was tested for the bond strength using the push-out test.

\section{Push-out bond strength}

To evaluate the effect of different irrigating solutions on bond strength, the second subgroup was subjected to a push-out test using a universal testing machine (Instron Co., Norwood, MA, USA). Samples were embedded in a cylindrical PVC mounting jig to facilitate perpendicular sectioning. The internal surface of the PVC mounting jig was coated with vaseline to facilitate removal of the specimen. To increase retention of embedded teeth, notches were created along the root surface. A clear self-curing specimen mounting material "Koldmount" (Vernon-Benshoff Company, Albany, NY, USA) was mixed according to the manufacturer's instructions and poured into the mounting ring and allowed to set for 20 minutes at room temperature $\left(75-80^{\circ} \mathrm{F}\right)$.
After complete setting of the acrylic, the mounted specimen was stabilized to a metallic base in a low speed diamond saw (Model 650; SBT South Bay Technology Inc., Arlington, VA, USA), and was sectioned in a perpendicular direction to the long axis of the root under water-cooling. The cutting sequence was as follows: the first $1 \mathrm{~mm}$ was discarded, the next $3 \mathrm{~mm}$ was obtained and labeled as cervical specimen, the next $2 \mathrm{~mm}$ section was discarded, and then the next 3 $\mathrm{mm}$ section was obtained and labeled as apical specimen.

A metallic device $7 \mathrm{~mm}$ in height, $2 \mathrm{~cm}$ in diameter, and with a central opening slightly larger than the diameter of the root canal orifice was used to hold the tooth sections. To insure the load was only concentrated on the cemented post, a $1.2 \mathrm{~mm}$ plunger which is slightly smaller than the diameter of the cemented post was used to apply the load at a rate of $1 \mathrm{~mm} / \mathrm{min}$ in an apical-coronal direction until the post dislodged.

\section{SEM analysis}

To evaluate the dentin surface when the post space preparation was completed, one tooth from each group was split in a longitudinal direction. In addition, to distinguish the quality and quantity of resin tag formation between coronal and apical sections of the post space after treatment with different endodontic irrigant solutions and post placement, the assigned specimens (two cervical specimens and two apical specimens) in each group were immersed in $37 \% \mathrm{HCl}$ for 6 hours to dissolve tooth substrate. The specimens were goldsputtered and imaged under a scanning electron microscope (Hitachi S-3200N Scanning Electron Microscope; Hitachi High-Technologies America Inc., Schaumburg, IL, USA). The resin tags were evaluated under $500 \times$ magnification, and the dentin surface was evaluated under $800 \times$ magnification

\section{Failure Analysis}

After push-out testing, the failed specimens were evaluated under a microscope to determine the failure mode according to the following:

1. Adhesive/tooth (cement debonded from dentin surface)

2. Adhesive/post (cement debonded from the post surface)

3. Cohesive: Cement (failure within cement layer)

4. Mixed failure: Indicated by comparable amounts of cement adhering to the post and radicular dentin.

\section{Statistical Analysis}

Mean and SD of bond strengths were calculated. Two-way ANOVA were used to analyze the interaction between the groups and positions. One-way ANOVA and Tukey multiple 
comparison tests were used to analyze the differences in bond strength between the irrigation groups at $P<0.05$. Independent $t$-tests were used to compare the bond strength between specimen positions for each solution group at $P<0.05$.

\section{Results}

\section{Push-out bond strength}

Two-way ANOVA showed there was significant difference between groups without looking to the positions and also showed significant difference between positions overall. The test also revealed there was also significant interaction between position and groups $(P<0.015)$ as shown in Table 1 .

One-way ANOVA compared groups within each position and revealed significant difference among the groups at $P<0.000$ (Table 2). Group two post space irrigated with EDTA had the highest bond strength $18.63 \pm 2.86 \mathrm{MPa}$ in the cervical position and $13.49 \pm 3.67 \mathrm{MPa}$ in the apical position. The specimens in the cervical positions in Group 3 had the next highest bond strength 11.22 $\pm 4.56 \mathrm{MPa}$. In Group 1, post spaces that were irrigated with $6.15 \% \mathrm{NaOCl}$ and Group 4 post space irrigated with $6.15 \% \mathrm{NaOCl}+0.12 \%$ chlorhexidine solution had the lowest bond strength. The irrigation with

Table I Two-way ANOVA comparing groups and positions

\begin{tabular}{llllll}
\hline Source & $\begin{array}{l}\text { Sum of } \\
\text { squares }\end{array}$ & df & $\begin{array}{l}\text { Mean } \\
\text { square }\end{array}$ & $\begin{array}{l}\text { Fisher } \\
\text { test }\end{array}$ & P-value \\
\hline Group & 1406.654 & 3 & 468.885 & 59.761 & $0.000^{\mathrm{a}}$ \\
Position & 217.647 & $\mathrm{I}$ & 217.647 & 27.740 & $0.000^{\mathrm{a}}$ \\
Group vs position & 87.305 & 3 & 29.102 & 3.709 & $0.015^{\mathrm{a}}$ \\
Error & 564.909 & 72 & 7.846 & & \\
Total & 8819.753 & 80 & & & \\
Corrected total & 2276.515 & 79 & & & \\
\hline
\end{tabular}

Notes: ${ }^{\text {V}}$ alues are significant at $P<0.05$.
$17 \%$ EDTA alone or in combination with $\mathrm{NaOCl}$ resulted in the highest bond strengths especially specimens in the cervical positions.

Independent $t$-test revealed comparisons of position within each group (Table 3). In Groups 2 and 3, there was a statistically significant difference between the specimens in the cervical and apical positions in the same group. However, in Groups 1 and 4 there was no statistically significant difference in the specimen position.

\section{Failure mode}

The failure mode in all groups was mainly adhesive at the dentin-cement interface (Table 4). In all assigned groups (Groups 1-4), the majority of specimens had adhesive failure $(80 \%, 60 \%, 70 \%$, and $75 \%$, respectively). Type B failure mode was rare in all groups; the highest finding was in Group 2 (15\%). The mixed failure was 15\% in Groups 1 and 2 , and $20 \%$ in Groups 3 and 4 . The cohesive failure was only observed in Group 2 (10\%).

Table 3 Independent $t$-test compared positions with each group

\begin{tabular}{|c|c|c|c|c|c|c|}
\hline \multirow[t]{2}{*}{ Group } & & \multirow[t]{2}{*}{ Mean } & \multirow[t]{2}{*}{ SD } & \multirow{2}{*}{$\begin{array}{l}\text { t-test } \\
P \text {-Value }\end{array}$} & \multicolumn{2}{|l|}{$95 \% \mathrm{Cl}$} \\
\hline & & & & & $\begin{array}{l}\text { Lower } \\
\text { bound }\end{array}$ & $\begin{array}{l}\text { Upper } \\
\text { bound }\end{array}$ \\
\hline \multirow[t]{2}{*}{ GI } & Cervical & 5.938 & 2.332 & 0.402 & 4.172 & 7.703 \\
\hline & Apical & 5.180 & 1.533 & & 3.414 & 6.946 \\
\hline \multirow[t]{2}{*}{ G2 } & Cervical & $|8.63|$ & 2.860 & $0.003^{a}$ & 16.866 & 20.397 \\
\hline & Apical & |3.49| & 3.672 & & 11.726 & 15.257 \\
\hline \multirow[t]{2}{*}{ G3 } & Cervical & II.224 & 4.560 & $0.004^{\mathrm{a}}$ & 9.458 & 12.990 \\
\hline & Apical & 5.656 & 2.357 & & 3.890 & 7.421 \\
\hline \multirow[t]{2}{*}{ G4 } & Cervical & 6.980 & 2.358 & 0.053 & 5.214 & 8.746 \\
\hline & Apical & 5.251 & 1.186 & & 3.485 & 7.016 \\
\hline
\end{tabular}

Notes: Group I: 6.15\% NaOCL. Group 2: 17\% EDTA. Group 3: 6.15\% NaOCL+17\% EDTA. Group 4: $6.15 \% \mathrm{NaOCL}+0.12 \% \mathrm{CHX}$. avalues are significant at $P<0.05$.

Table 2 One-way ANOVA compared groups within each position

\begin{tabular}{|c|c|c|c|c|c|c|c|c|c|c|c|}
\hline \multirow[t]{2}{*}{ Position } & \multirow[t]{2}{*}{ Group } & \multirow[t]{2}{*}{$\mathbf{N}$} & \multirow[t]{2}{*}{ Mean } & \multirow[t]{2}{*}{ SD } & \multirow{2}{*}{$\begin{array}{l}\text { ANOVA } \\
P \text {-value }\end{array}$} & \multicolumn{2}{|c|}{$95 \% \mathrm{Cl}$ for mean } & \multicolumn{4}{|c|}{ Tukey as multiple comparison test } \\
\hline & & & & & & $\begin{array}{l}\text { Lower } \\
\text { bound }\end{array}$ & $\begin{array}{l}\text { Upper } \\
\text { bound }\end{array}$ & $\overline{\mathbf{G I}}$ & G2 & G3 & G4 \\
\hline \multirow[t]{4}{*}{ Cervical } & GI & 10 & 5.938 & 2.332 & $0.000^{\mathrm{a}}$ & 4.269 & 7.606 & 1 & & & \\
\hline & G2 & 10 & $|8.63|$ & 2.860 & & 16.586 & 20.677 & 0.000 & I & & \\
\hline & G3 & 10 & 11.224 & 4.560 & & 7.962 & 14.486 & 0.003 & 0.000 & $\mathrm{I}$ & \\
\hline & G4 & 10 & 6.980 & 2.358 & & 5.293 & 8.667 & $0.88 \mathrm{I}$ & 0.000 & 0.024 & $\mathrm{I}$ \\
\hline \multirow[t]{4}{*}{ Apical } & GI & 10 & 5.180 & $\mathrm{I} .533$ & $0.000^{\mathrm{a}}$ & 4.083 & 6.277 & $\mathrm{I}$ & & & \\
\hline & G2 & 10 & $|3.49|$ & 3.672 & & 10.864 & 16.118 & 0.000 & 1 & & \\
\hline & G3 & 10 & 5.656 & 2.357 & & 3.969 & 7.342 & 0.970 & 0.000 & I & \\
\hline & G4 & 10 & 5.251 & 1.186 & & 4.402 & 6.099 & 0.990 & 0.000 & $0.98 I$ & 1 \\
\hline
\end{tabular}

Notes: Group I: 6.15\% NaOCL. Group 2: 17\% EDTA. Group 3: 6.15\% NaOCL+17\% EDTA. Group 4: 6.15\% NaOCL+0.12\% CHX. aValues are significant at $P<0.05$. 
Table 4 Failure modes for all groups

\begin{tabular}{lllll}
\hline Failure modes & $\begin{array}{l}\text { Group I } \\
\text { specimens (\%) }\end{array}$ & $\begin{array}{l}\text { Group 2 } \\
\text { specimens (\%) }\end{array}$ & $\begin{array}{l}\text { Group 3 } \\
\text { specimens (\%) }\end{array}$ & $\begin{array}{l}\text { Group 4 } \\
\text { specimens (\%) }\end{array}$ \\
\hline Failure type A adhesive/tooth & $16(80 \%)$ & $12(60 \%)$ & $14(70 \%)$ & $15(75 \%)$ \\
Failure type B adhesive/post & $1(5 \%)$ & $3(15 \%)$ & $2(10 \%)$ & $1(5 \%)$ \\
Mixed failure A \& B & $3(15 \%)$ & $3(15 \%)$ & $4(20 \%)$ & $4(20 \%)$ \\
Failure type C cohesive/cement & & $2(10 \%)$ & & \\
\hline
\end{tabular}

Notes: Group I: 6.15\% NaOCL. Group 2: 17\% EDTA. Group 3: 6.15\% NaOCL+17\% EDTA. Group 4: 6.15\% NaOCL+0.12\% CHX.

\section{SEM analysis}

The smear layer removed from the root canal surface was affected by the irrigating solution that was used in each group and consequently affected the resin tag formation.

In Group 1, irrigated with $6.15 \% \mathrm{NaOCl}$, the smear layer was partially removed from the specimens in the cervical position but remained in the apical positions. In the specimens at the cervical position, the length and amount of resin tags were better than the specimens in the apical position. There were several limited areas where the resin tags extended into the dentinal tubules, but these resin tags were scattered along the post surface (Figure 1).
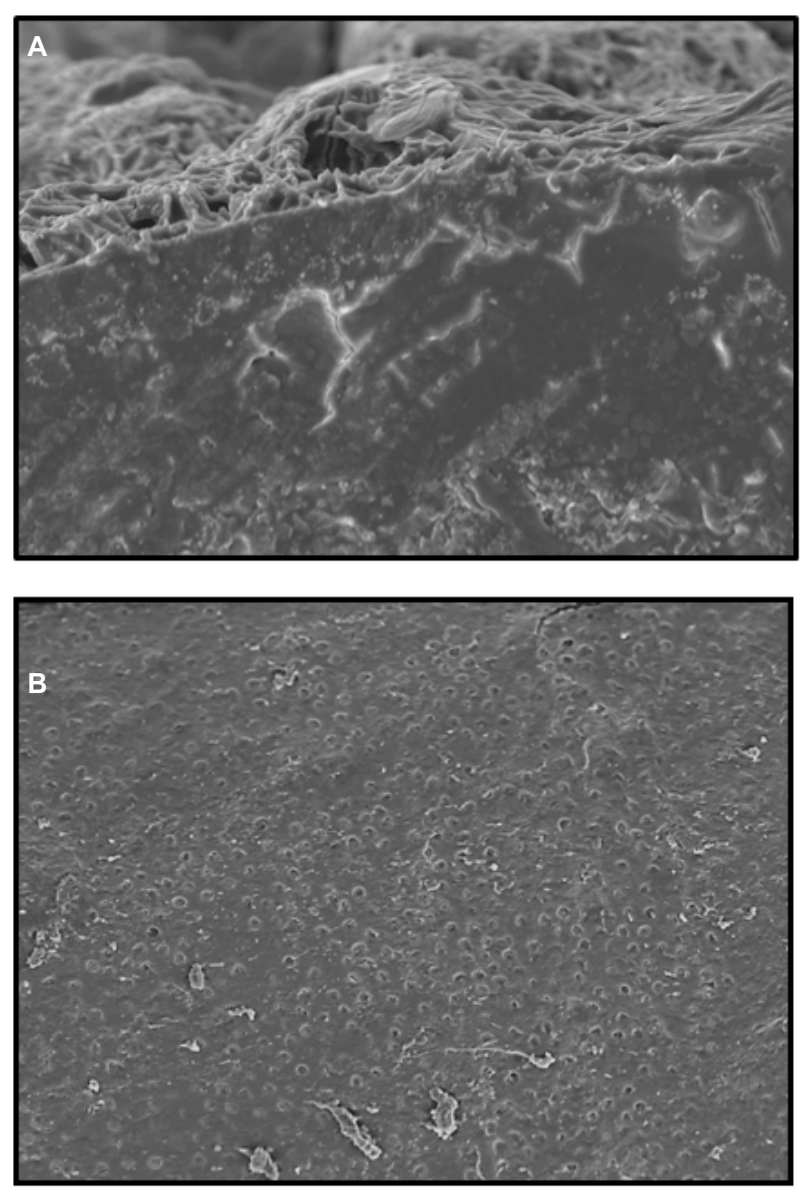

Figure I SEM from Group I: Resin tags and dentine tubules in the cervical (A, B) and in the apical (C, D) regions.
In Group 2, irrigated by 17\% EDTA, the smear layer was removed completely along the entire post space. Therefore, the resin tag quality and quantity were much better than all other groups. The specimens in both cervical and apical positions, the entire surface of the post space was covered by long and distinct resin tags infiltrating into dentinal tubules. However, the quality of resin tags in the specimens in the cervical position was better than the resin tags in the apical position (Figure 2).

In Group 3, irrigated with a combination of $6.15 \%$ $\mathrm{NaOCl}+17 \%$ EDTA, the smear layer and debris were completely removed along the entire post space. In the cervical
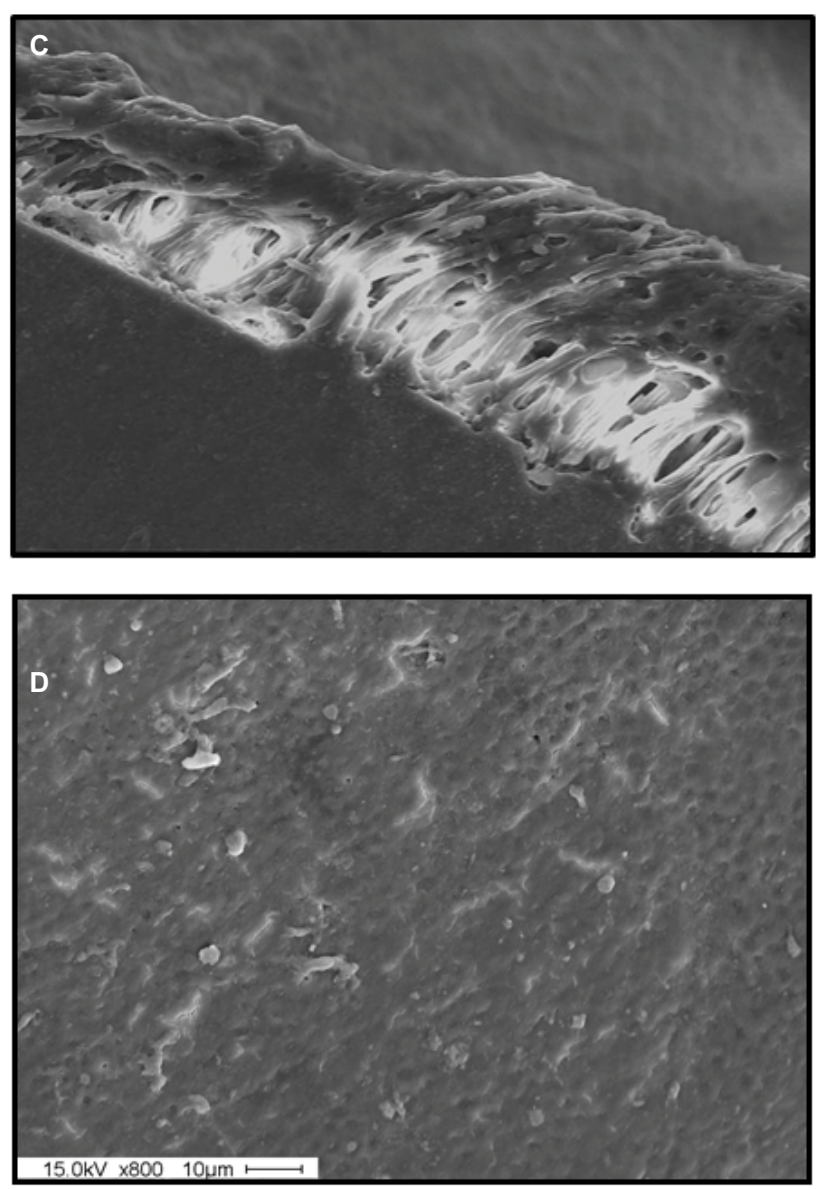

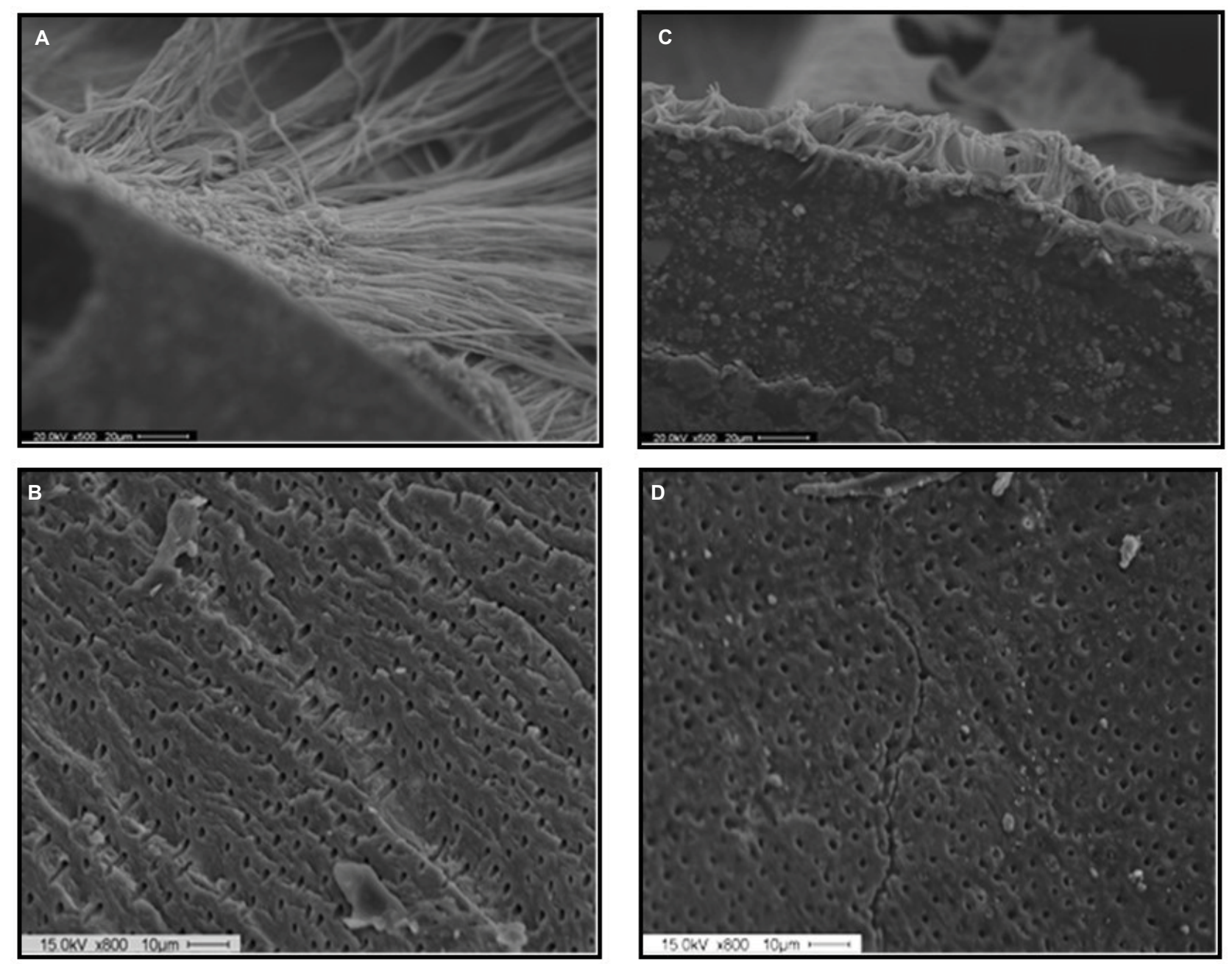

Figure 2 SEM from Group 2: Resin tags and dentine tubules in the cervical (A, B) and in the apical (C, D) regions.

third, the surface was cleaned and the dentinal tubules were opened. However, in the apical third of the post space, the surface was cleaned but only partially opened the dentinal tubules. Also, the entire post space was completely covered by the resin tags extending into the dentinal tubules, especially in the cervical specimens. The resin tags in the cervical specimens were longer and more distinct than the tags in the apical specimens (Figure 3).

In Group 4, irrigated with $6.15 \% \mathrm{NaOCl}+0.12 \%$ chlorhexidine, the smear layer and debris were removed partially from the entire dentin surface. There were several small scattered resin tags formed along the post space extending into the dentinal tubules, with no difference in quality and quantity between the coronal and apical portions (Figure 4).

\section{Discussion}

In the present study, standard root canal treatment protocol was followed with full strength $\mathrm{NaOCl}$ as the primary irrigant solution during the instrumentation procedure, and then final flush with 17\% EDTA to remove the non-organic content of radicular dentin. A parallel post diameter was selected instead of a tapered post diameter to create a uniform thin layer of cement between the post surface and the dentin surface along the entire post space. In this study, the effect of different endodontic irrigant solutions on the bond strength of cemented fiber post was investigated through a push-out test, which is considered to be the most reliable test to measure the bond strength inside root canal since it simulates what is happening in the clinical situation. 

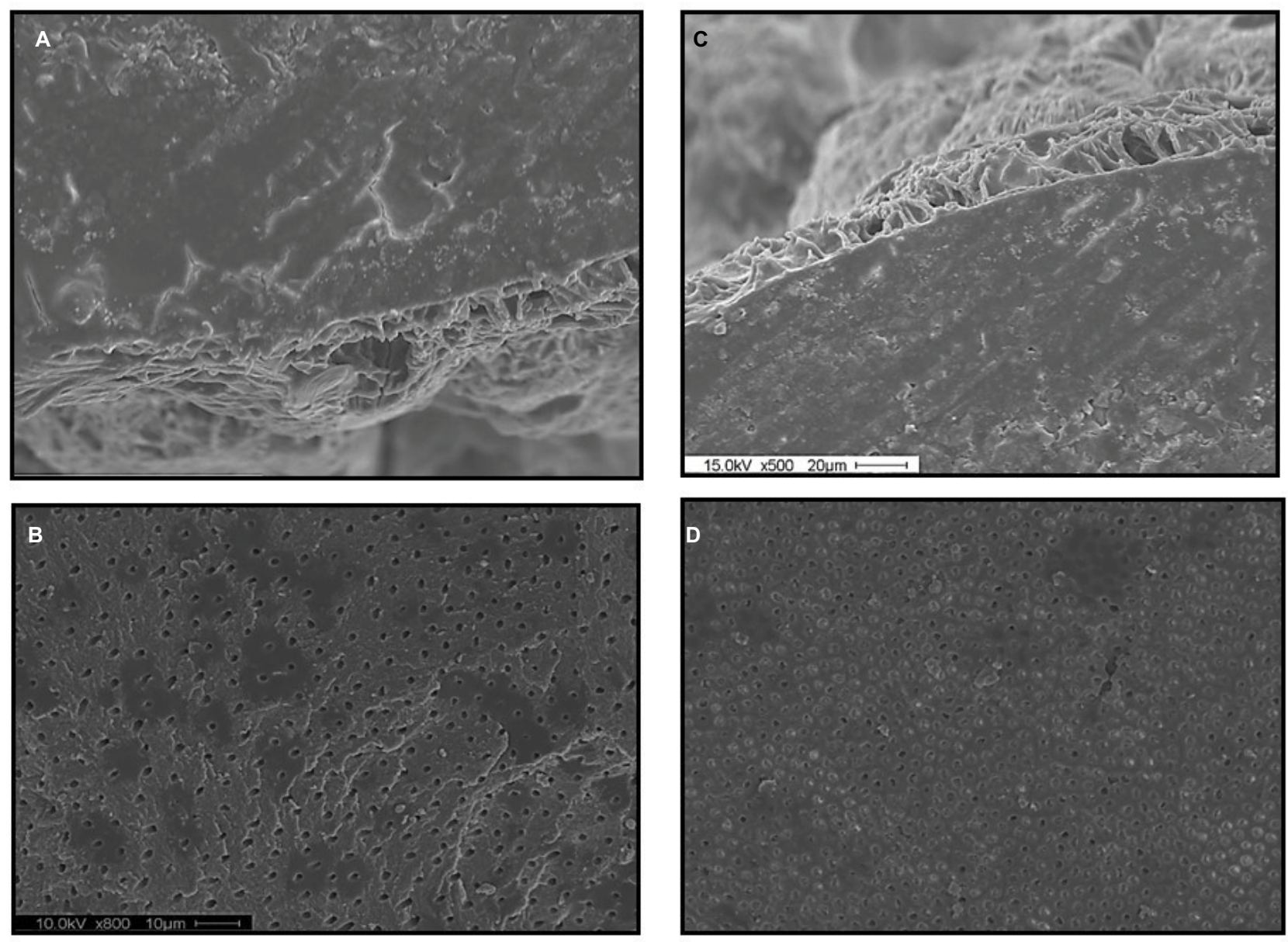

Figure 3 SEM from Group 3: Resin tags and dentine tubules in the cervical (A, B) and in the apical (C, D) regions.

Based on the results of the present study, the groups that were irrigated with $6.16 \% \mathrm{NaOCl}$ had lower bond strength values than the groups that were irrigated with $17 \%$ EDTA. Other studies reported that $\mathrm{NaOCl}$ reduces the bond strength of cemented fiber post with luting resin cements. ${ }^{19-21} \mathrm{NaOCl}$ reacts with dentin and breaks down into chlorine and oxygen. It is thought that the liberation of oxygen inhibits the polymerization process of the luting cement and interferes with resin infiltration into dentinal tubules. ${ }^{17}$ EDTA showed higher bond strength values due to the efficacy of EDTA to remove the smear layer and open the dentinal tubules. ${ }^{15,22}$ Chlorhexidine had no effect on the bond strength because it is a non-oxidizing agent. However, the SEM pictures of the post space irrigated with $\mathrm{NaOCl}$ and flushed with chlorhexidine revealed precipitate formation along the entire radicular dentin (Figure 4). The combination of $\mathrm{NaOCl}$ and EDTA was found to be very effective in removing the smear layer in the root canal especially in the cervical portion. The oxygen liberation from the $\mathrm{NaOCl}$ probably will reduce the bond strength results, especially in the apical specimens.

In the light of the present study, the push-out bond strength results were found to be statistically different. Thus the null hypothesis was rejected. The push-out bond strength results that were obtained in this study are in agreement with Morris et $\mathrm{al}^{12}$ and Ari et $\mathrm{al}^{13}$ findings. They reported that $\mathrm{NaOCl}$ had an adverse effect on the bond between radicular dentin and luting resin cement. In addition, Perdigao et al ${ }^{16}$ found that the bond strength of cervical specimens was higher than the apical specimens which is in agreement with our findings. Moreover, they found that the bond strength of teeth irrigated with $\mathrm{NaOCl}$ was within $6 \mathrm{MPa}$, which is also similar to our findings.

Pereira et $\mathrm{al}^{23}$ found that the bond strength of fiber posts to root dentin varies depending on the cement used for post cementation, gap-free interfaces produces high interfacial strength, and the post level did not influence the bond strength of fiber posts to root dentin. The retention of fiber posts is 
A
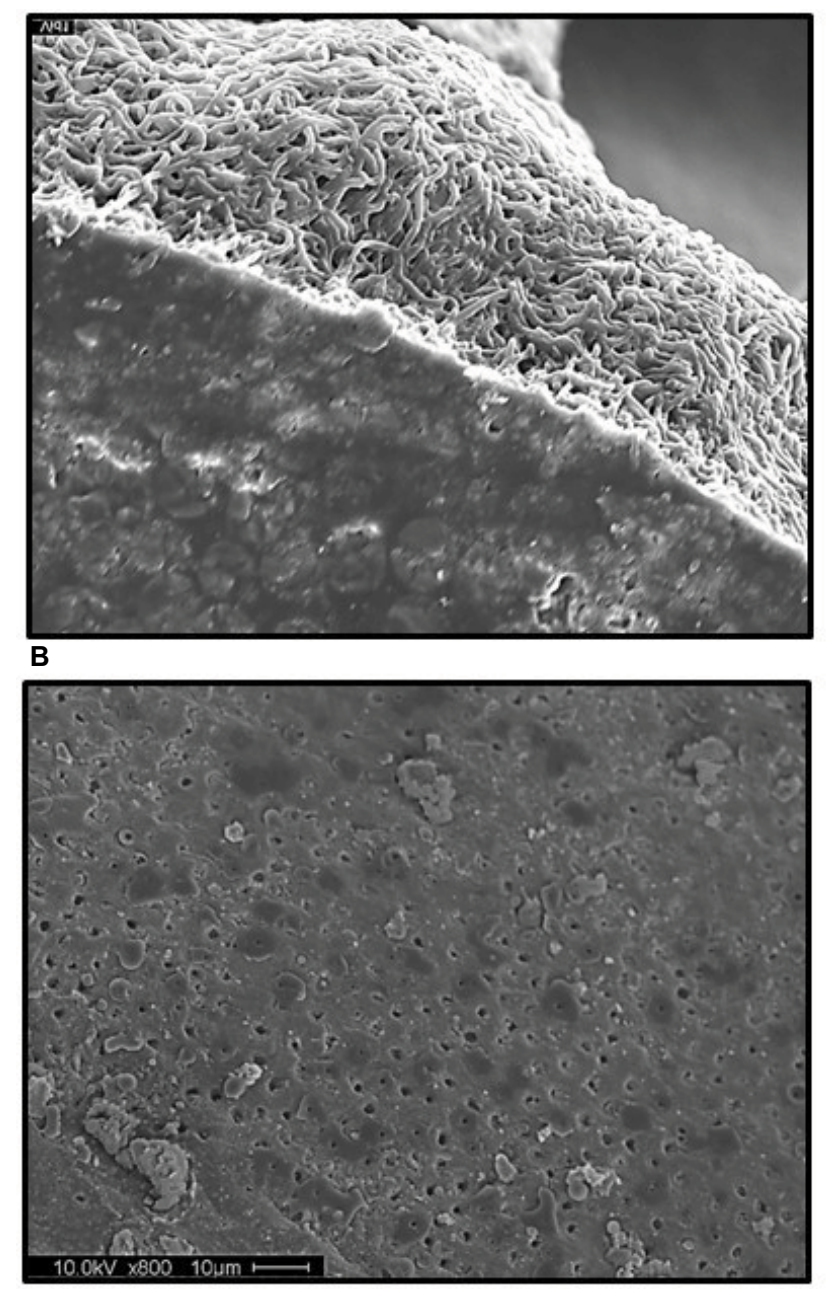

C

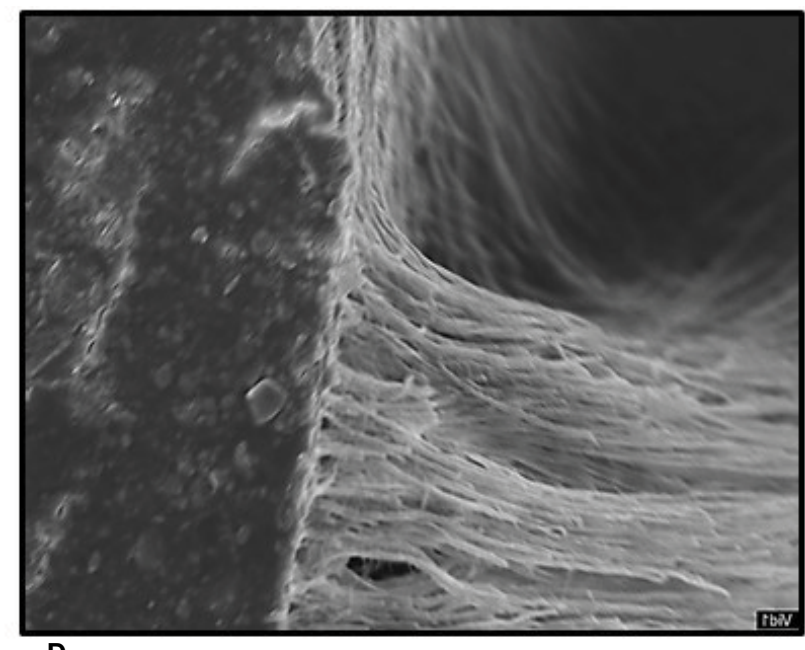

D

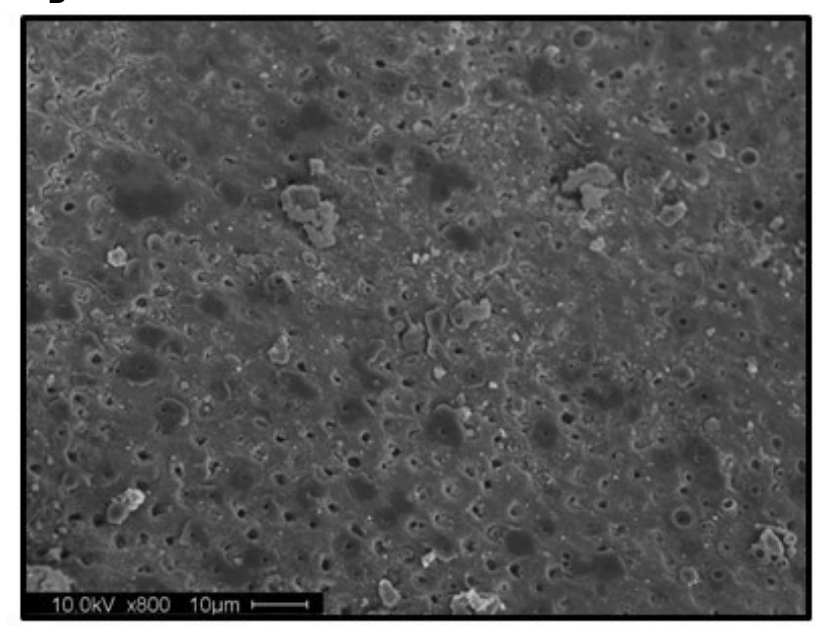

Figure 4 SEM from Group 4: Resin tags and dentine tubules in the cervical (A, B) and in the apical (C, D) regions.

dependent on the firm and lasting adhesion between resin cement and the dentine. ${ }^{24}$

SEM findings in this study were correlated to the pushout strength findings. The capability of each assigned irrigant solution to remove the smear layer plays an important role in the resin tag infiltration into dentinal tubules and consequently the bond strength between dentin and resin cement. ${ }^{25-27}$ EDTA irrigant solution was more effective in removing the smear layer than the $\mathrm{NaOCl}$. EDTA removed most of the smear layer especially in the cervical region and opened the dentinal tubules. However, $\mathrm{NaOCl}$ was less effective at removing the smear layer and partially opened the dentinal tubules. Chlorhexidine produced a precipitate that affects dentinal tubules patency. In all groups, the cervical region was cleaner and dentinal tubules were more patent than the apical area. This phenomenon explains why the bond strength in the cervical specimens was higher than in the apical specimens. Another reason that might contribute to the difference in the bond strength between different specimen locations is the anatomy of the root canal. Different root canal regions show different densities and distributions of dentinal tubules. ${ }^{8}$ Dentinal tubule density in the cervical area of radicular dentin is higher than in the apical area. Therefore, the adhesion of resin cement to cervical dentin is expected to be better than the adhesion of cement in the apical region.

The bonding strength is not related to the length of resin tags. Therefore, the relation between resin tags formation and bond strength is correlated with adhesion location (cervical vs apical) and also with the angulation of dentinal tubules (perpendicular vs parallel). ${ }^{28,29}$ Different studies found that there is no correlation between the resin tags length and the bond strength. Resin tags are mainly effective in sealing the dentin. ${ }^{30}$

The failure mode in this study was mainly adhesive between the dentin and resin cement (Table 2). These results 
agree with Zicari et $\mathrm{al}^{6}$ and Bitter et $\mathrm{al}^{26}$ findings. This may be explained by the inability of the self-adhesive resin cement to form a distinct hybrid layer between dentin and resin tags like the etch-and-rinse ${ }^{8}$ cements and, therefore, unable to demineralize the dentin surface and etch a thick smear layer. ${ }^{9}$ In all groups that were irrigated with $\mathrm{NaOCl}$, the failure mode was mostly in the dentin-cement interface which means either the cement could not dissolve the smear layer and demineralize the dentin substructure or that the residual chemical adversely affected the bonding process.

Cunha et $\mathrm{al}^{31}$ indicated that shear bond strength is significantly influenced by irrigation protocols. The use of $\mathrm{NaOCL}$ before adhesive techniques may have negative effects due to its time-dependent process and is dependent on the type of adhesive.

Since $\mathrm{NaOCl}$ is the primary endodontic irrigant solution $^{10,11}$ and since its adverse effect on the bonding strength was reported..$^{15,16}$ Using an anti-oxidant agent before post cementation is advised. Although using adhesive resin system is gaining more popularity, ${ }^{1}$ the future adhesive resins should incorporate an anti-oxidant agent to overcome the impact of an endodontic irrigant solution containing hypochlorite.

\section{Conclusion}

1. $\mathrm{NaOCl}$ had an adverse effect on the bond strength of self-adhesive resin cement to radicular dentin.

2. EDTA irrigant solution improved the bond strength of self-adhesive resin with radicular dentin in both cervical and apical sections.

3. EDTA irrigant solution was more effective in removing the smear layer than $\mathrm{NaOCl}$.

4. Chlorhexidine used in conjunction with $\mathrm{NaOCl}$ did not have any effect on the bond strength; however it created a precipitate that might affect the patency of dentinal tubules.

\section{Acknowledgments}

A part in the abstract of this manuscript was presented as a poster in the FDI Annual World Dental Congress in August 2013 in Istanbul, Turkey. The authors also wish to thank Delta Dental Foundation for partially funding this research.

\section{Disclosure}

The authors report no conflicts of interest in this work.

\section{References}

1. Morgano SM, Hashem AF, Fotoohi K, Rose L. A nationwide survey of contemporary philosophies and techniques of restoring endodontically treated teeth. J Prosthet Dent. 1994;72(3):259-267.
2. Duret B, Reynaud M, Duret F. A new concept of corono-radicular reconstruction, the Composipost (2). Chir Dent Fr. 1990;60(542):69-77.

3. Sorensen JA, Martinoff JT. Intracoronal reinforcement and coronal coverage: a study of endodontically treated teeth. J Prosthet Dent. 1984;51(6):780-784.

4. Schwartz RS, Robbins JW. Post placement and restoration of endodontically treated teeth: a literature review. J Endod. 2004;30(5):289-301.

5. Bitter K, Kielbassa AM. Post-endodontic restorations with adhesively luted fiber-reinforced composite post systems: a review. Am J Dent. 2007;20(6):353-360.

6. Zicari F, Couthino E, de Munck J, et al. Bonding effectiveness and sealing ability of fiber-post bonding. Dent Mater. 2008;24(7):967-977.

7. Yiu CK, García-Godoy F, Tay FR, et al. A nanoleakage perspective on bonding to oxidized dentin. J Dent Res. 2002;81(9):628-632.

8. de Munck J, Vargas M, van Landuyt K, Hikita K, Lambrechts P, van Meerbeek B. Bonding of an auto-adhesive luting material to enamel and dentin. Dent Mater. 2004;20(10):963-971.

9. Rathke A, Haj-Omer D, Muche R, Haller B. Effectiveness of bonding fiber posts to root canals and composite core build-ups. Eur J Oral Sci. 2009;117(5):604-610.

10. Byström A, Sundqvist G. Bacteriologic evaluation of the efficacy of mechanical root canal instrumentation in endodontic therapy. Scand $J$ Dent Res. 1981;89(4):321-328.

11. Ohara P, Torabinejad M, Kettering JD. Antibacterial effects of various endodontic irrigants on selected anaerobic bacteria. Endod Dent Traumatol. 1993;9(3):95-100.

12. Morris MD, Lee KW, Agee KA, Bouillaguet S, Pashley DH. Effects of sodium hypochlorite and RC-prep on bond strengths of resin cement to endodontic surfaces. J Endod. 2001;27(12):753-757.

13. Ari $\mathrm{H}$, Yaşar E, Belli S. Effects of $\mathrm{NaOCl}$ on bond strengths of resin cements to root canal dentin. J Endod. 2003;29(4):248-251.

14. Perdigao J, Denehy GE, Swift EJ. Effects of chlorhexidine on dentin surfaces and shear bond strengths. Am J Dent. 1994;7(2):81-84.

15. Gu XH, Mao CY, Kern M, Xh G, Liang C, Wang HM. Effect of different irrigation on smear layer removal after post space preparation. J Endod. 2009;35(4):583-586.

16. Perdigão J, Lopes M, Geraldeli S, Lopes GC, García-Godoy F. Effect of a sodium hypochlorite gel on dentin bonding. Dent Mater. 2000;16(5): 311-323.

17. Rueggeberg FA, Margeson DH. The effect of oxygen inhibition on an unfilled/filled composite system. J Dent Res. 1990;69(10):1652-1658.

18. Lai SC, Mak YF, Cheung GS, et al. Reversal of compromised bonding to oxidized etched dentin. J Dent Res. 2001;80(10):1919-1924.

19. Erdemir A, Ari H, Güngüneş H, Belli S. Effect of medications for root canal treatment on bonding to root canal dentin. J Endod. 2004;30(2): $113-116$.

20. Nikaido T, Takano Y, Sasafuchi Y, Burrow MF, Tagami J. Bond strengths to endodontically-treated teeth. Am J Dent. 1999;12(4):177-180.

21. Hayashi M, Takahashi Y, Hirai M, Iwami Y, Imazato S, Ebisu S. Effect of endodontic irrigation on bonding of resin cement to radicular dentin. Eur J Oral Sci. 2005;113(1):70-76.

22. Carvalho AS, Camargo CH, Valera MC, Camargo SE, Mancini MN. Smear layer removal by auxiliary chemical substances in biomechanical preparation: a scanning electron microscope study. $J$ Endod. 2008;34(11):1396-1400.

23. Pereira JR, Rosa RA, Só MV, et al. Push-out bond strength of fiber posts to root dentin using glass ionomer and resin modified glass ionomer cements. J Appl Oral Sci. 2014;22(5):390-396.

24. Yu HH, Zhang L, Xu S, et al. Effects of Epigallocatechin-3-gallate (EGCG) on the bond strength of fiber posts to Sodium hypochlorite $(\mathrm{NaOCl})$ treated intraradicular dentin. Sci Rep. 2017;7(1):4235.

25. Ferrari M, Mannocci F, Vichi A, Cagidiaco MC, Mjör IA. Bonding to root canal: structural characteristics of the substrate. Am J Dent. 2000;13(5):255-260.

26. Bitter K, Meyer-Lueckel H, Priehn K, Kanjuparambil JP, Neumann K, Kielbassa AM. Effects of luting agent and thermocycling on bond strengths to root canal dentine. Int Endod J. 2006;39(10):809-818. 
27. Pashley DH, Ciucchi B, Sano H, Horner JA. Permeability of dentin to adhesive agents. Quintessence Int. 1993;24(9):618-631.

28. Pashley DH. Clinical correlations of dentin structure and function. J Prosthet Dent. 1991;66(6):777-781.

29. Gwinnett AJ. Quantitative contribution of resin infiltration/hybridization to dentin bonding. Am J Dent. 1993;6(1):7-9.
30. Tao L, Pashley DH. Shear bond strengths to dentin: effects of surface treatments, depth and position. Dent Mater. 1988;4(6):371-378.

31. da Cunha LF, Furuse AY, Mondelli RF, Mondelli J. Compromised bond strength after root dentin deproteinization reversed with ascorbic acid. J Endod. 2010;36(1):130-134.

\section{Publish your work in this journal}

Clinical, Cosmetic and Investigational Dentistry is an international, peer-reviewed, open access, online journal focusing on the latest clinical and experimental research in dentistry with specific emphasis on cosmetic interventions. Innovative developments in dental materials, techniques and devices that improve outcomes and patient satisfac- tion and preference will be highlighted. The manuscript management system is completely online and includes a very quick and fair peerreview system, which is all easy to use. Visit http://www.dovepress. com/testimonials.php to read real quotes from published authors. 